Research Article

\title{
Study on the Spatially Variable Saturated Hydraulic Conductivity and Deformation Behavior of Accumulation Reservoir Landslide Based on Surface Nuclear Magnetic Resonance Survey
}

\author{
Shu Zhang $\mathbb{D}^{1},{ }^{1}$ Yunshan Xiahou, ${ }^{1}$ Huiming Tang $\mathbb{D}^{1,2}$ Lei Huang $\mathbb{D}^{2},{ }^{2}$ Xiao Liu, ${ }^{1}$ \\ and Qiong $W \mathbf{u}^{2}$
}

${ }^{1}$ Three Gorges Research Center for Geo-Hazard, China University of Geosciences, Wuhan, Hubei 430074, China

${ }^{2}$ Faculty of Engineering, China University of Geosciences, Wuhan, Hubei 430074, China

Correspondence should be addressed to Shu Zhang; szhang@cug.edu.cn and Huiming Tang; tanghm@cug.edu.cn

Received 15 June 2018; Accepted 24 September 2018; Published 23 October 2018

Guest Editor: Yongfeng Deng

Copyright (C) 2018 Shu Zhang et al. This is an open access article distributed under the Creative Commons Attribution License, which permits unrestricted use, distribution, and reproduction in any medium, provided the original work is properly cited.

\begin{abstract}
Saturated hydraulic conductivity $\left(K_{\mathrm{s}}\right)$ is spatially variable in accumulation landslide sites that exert significant effort onto landslide seepage and deformation behavior. To better understand spatial variability and the effect of $K_{\mathrm{s}}$ on the slide mass of an accumulation landslide, this study introduced the surface nuclear magnetic resonance (SNMR) technology to study a representative reservoir accumulation landslide field in the Three Gorges Reservoir area (TGRA), the Baishuihe landslide, to obtain a series of relative reliable spatial measurements of $K_{s}$ effectively on the basis of calibration in terms of the field tests measurements. The estimated $K_{\mathrm{s}}$ values were distributed log-normally for the overall landslide mass site with a wide range of $3.00 \times 10^{-6} \sim 7.80 \times$ $10^{-3} \mathrm{~cm} / \mathrm{s}$, which reaches about 3 orders of magnitude. Variogram analysis indicated that the $K_{\mathrm{s}}$ values have the range $(A)$ of $295.89 \mathrm{~m}$ and $65.56 \mathrm{~m}$ for the overall site and major cross-sectional analysis, respectively. A finite-element seepage-stress analysis associated with a Kriging-interpolated spatial $K_{\mathrm{s}}$ variable calculation model based on the best-fitted theoretical variogram was subsequently performed to study the seepage and deformation behavior of the landslide. The available monitored data and simulated results of the finite-element seepage-stress analysis indicated that the Baishuihe landslide is a progressive landslide, and the main factor influencing the deformation is rainfall and reservoir water fluctuation. This study provides an unconventional framework for studying the heterogeneous geomaterial and contributes to a better understanding of the spatial variation of the hydraulic property of accumulation reservoir landslides at a field scale.
\end{abstract}

\section{Introduction}

Accompanied by the reservoir operation of hydropower projects, reservoir landslides have become a typical geohazard in reservoir areas in the world $[1,2]$. The instability of the reservoir landslide may arouse devastating economic and social costs, even the loss of human life. Under the combined effect of reservoir water-level fluctuation and rainfall, saturated hydraulic conductivity $\left(K_{s}\right)$ is a key soil hydraulic parameter, which controls the water seepage process, determines water distribution, and thus exerts a dominant impact on landslide deformation and instability [3-6].

It is generally accepted that $K_{\mathrm{s}}$ is characterized by spatial variability at different scales due to the parent material and environmental process [7-10]. However, $K_{\mathrm{s}}$ values are usually assumed to be identical and are generally derived from experiments of a few samples. The variations of the values derived from the characteristics of discontinuity, heterogeneity, and anisotropy have not been taken into account in this assumption [11]. In this sense, the understanding of spatial variability of hydrological properties 
should be taken into account when performing a landslide analysis.

Considerable research studies have been devoted to investigate the regional-scale variation, probability distribution pattern, and geostatistic-based spatial variation of measured $K_{\mathrm{s}}$ values of different geomaterials, such as loessial soil $[10,11]$, river sediments [12-14], alluvial floodplains [15], and costal farmlands [16]. $K_{\mathrm{s}}$ exhibits significant spatial variation and autocorrelation in the aforementioned research studies regardless of homogeneous or heterogeneous geomaterials. However, the research involving $K_{\mathrm{s}}$ field-scale spatial variation of the accumulation reservoir landslide is still insufficient.

Different techniques have been employed to evaluate $K_{\mathrm{s}}$ both in the laboratory and in the field. Laboratory permeameter tests have the challenge of introducing errors induced by soil disturbance during sampling and transportational processes. In addition, the sampled soil is deprived of other dominant hydraulic effects presented in the field [17]. By contrast, field methods (instrumental methods and hydrogeophysical methods) address the soil in the field condition; thus, the small-scale heterogeneities caused by the soil structure, composition, texture, plant growth, and other factors may contribute to the measuring results [11]. Other than the widely adopted direct/indirect instrumental methods, hydrogeophysical methods utilized the link between what can be measured with geophysical instruments and the subsurface hydrological properties using a noninvasive process, thus providing cost-effective and relatively dense spatial information about the site of research interest. Among these hydrogeophysical methods, nuclear magnetic resonance (NMR) is a promising method for characterizing groundwater systems, which measure the NMR response of water molecules excitated by electromagnetic pulses $[18,19]$. It is applied as surface NMR (SNMR), borehole NMR (BNMR), and laboratory NMR (lab-NMR).

SNMR technology is a noninvasive surface-based method, which can be used to derive information about the pore structure and hydraulic conductivity of the formation from the empirical relations of determined water content and the relaxation time without the need to drill boreholes [20-22]. Some studies have utilized SNMR to distinguish the underlying formations of landslide [23], but further application of SNMR to landslide studies has not been extensively investigated to date.

In this sense, the objective of this study are (1) to apply the SNMR technology to a representative accumulation reservoir landslide in TGRA and estimate spatial $K_{\mathrm{s}}$ values of the subsurface colluvial-deluvial geomaterials based on newest comprehensive geotechnical investigation; (2) to perform descriptive statistics and analyze the spatial variation of the estimated $K_{s}$ values; and (3) to investigate the effect of spatially variable $K_{\mathrm{s}}$ to the deformation behavior of the landslide under the combinative effect of reservoir water fluctuation and rainfall through a $2 \mathrm{D}$ numerical simulation.

\section{SNMR Method}

2.1. Basics of SNMR. The magnetic spin is an inherent property of an atom that possesses an angular momentum, with an associated magnetic moment. Under the action of the stable earth's stable magnetic field, the hydrogen protons spin continuously in a precess motion about the magnetic field axis at the characteristic proton Larmor frequency, which is proportional to the magnetogyric ratio of the intensity of the earth's magnetic field and atomic nucleus. The orientation of the static field and the plane of precession perpendicular to it are commonly referred to as longitudinal direction and transverse direction, respectively [18]. During the process of the SNMR survey, an alternating current with the resonance of Larmor frequency is supplied to the large surface-based wire-loop transmitter, which is typically a circular or square loop of $50-100 \mathrm{~m}$ in diameter/edge length. A slight macroscopic spin magnetization moment is produced at the same time by the excitation pulse of the oscillating current. When the current pulse is terminated, magnetic resonance signals produced by the excitation of different pulse moments can be explored by the same surface-based transmitting coil. After an instrument delay known as "dead time" ( $\left.\tau_{\text {dead }}\right)$, the magnetic resonance signal can be measured and expressed as follows:

$$
e(t)=E_{0} \exp \left(\frac{-t}{T_{2}^{*}}\right) \cos \left(2 \pi f_{0} t+\varphi_{0}\right),
$$

where $E_{0}$ is the initial amplitude of the signal, which can be obtained by the measured amplitude $E_{0 \mathrm{~d}}$ and the relaxation time $T_{2}^{*}$ as $E_{0}=E_{0 \mathrm{~d}} \exp \left(\tau_{\text {dead }} / T_{2}^{*}\right)$, and $f_{0}$ and $\varphi_{0}$ denote the initial frequency and initial phase, respectively. The phase $\varphi_{0 \mathrm{~d}}$ correlates with the electrical conductivity of the geomaterials, but it is not currently used for SNMR data interpretation. With regard to the relaxation time, it is believed that $T_{2}^{*}$ is susceptible to the disturbance of electromagnetic noise; therefore, $T_{1}^{*}$ is adopted for hydrological parameter interpretation [18]. The strength of the signal and rate of decay are related to the magnitude of hydrogen protons in groundwater molecules. In other words, the amplitude of the magnetic resonance signal is proportional to the free water content of the surveyed area [24].

2.2. SNMR-Determined Hydrological Properties. The SNMR technology provides a strategy for estimating how hydrological parameters (e.g., porosity, water content, permeability, transmissivity, etc.) of the aquifer can be estimated $[18,19]$. The initial signal amplitude $E_{0 \mathrm{~d}}$ is proportional to the number of protons in the measured sample, which is equivalent to the volume of water in the measured sample [25], so the SNMRestimated effective porosity $(\varnothing)$ can be determined from $E_{0 \mathrm{~d}}$ using an instrument-specific calibration factor.

With regard to hydraulic conductivity estimation, Schlumberger-Doll Research (SDR) models give an equation to estimate the permeability $k_{\mathrm{SDR}}[26]$ :

$$
k_{\mathrm{SDR}}=b \varnothing^{m}\left(T_{2(1) \mathrm{ML}}\right)^{n},
$$


where $b, n$, and $m$ are the empirical constants and $T_{2(1) \mathrm{ML}}$ is used to present the average surface-area-to-value ratio of the pore of the entire saturated pore space, which can be replaced by $T_{2(1)}$ or $T_{2(1)}^{*}$. Under the condition of the unconsolidated near-surface aquifer material as we measured, $n=2$ and $m=1, b$ is regarded as a turning parameter to obtain the best possible match between the measurement and estimation [27-29]. Therefore, hydraulic conductivity $K$ can be related to $k$ by the equation $K=((\rho g) / \mu) k$, where $g=$ $9.8 \mathrm{~m} / \mathrm{s}^{2}$ is the gravitational acceleration, $\mu$ is the temperature-dependent dynamic viscosity, and $\rho$ is the temperature-dependent density, which can be determined in terms of table lookup according to the temperature.

For all of the analyses above, the physical constants can be absorbed into the constant $b^{\prime}$ in the SDR equation as follows:

$$
K_{\mathrm{SDR}}=b^{\prime} \cdot \varnothing \cdot T_{1}^{* 2},
$$

where $b^{\prime}$ should be calibrated based on the temperature as well as the drilling data and other forms of measurement on core samples for the requirement of accuracy [29].

\section{Case Study: The Baishuihe Landslide}

3.1. Background. The Baishuihe landslide is a typical accumulation reservoir landslide in TGRA. It is located on the south bank of the Yangtze River, $56 \mathrm{~km}$ west of the Three Gorges Dam (Figures 1(a) and 1(b)), with the main sliding direction of $20^{\circ}$ with respect to the north. It produced remarkable deformation since the first impoundment of the Three Gorges Reservoir in 2003 and has a great influence on the shipping safety of Yangtz River. The multiyear timedisplacement data of the landslide surface obtained from GPS monitoring exhibited a step-like pattern, which aroused much research attention [30-33]. However, most previous research studies aimed at predicting the deformation behavior and paid little attention to the engineering geological model and landslide mechanism.

The sophisticated engineering surveys involving 23 boreholes with a total length of $699.20 \mathrm{~m}$ and 14 exploratory trenches with a total volume of $101.24 \mathrm{~m}^{3}$ (shown in Figure 1(c)) have been carried out by Sanxia University in 2012 and China university of Geosciences, Wuhan, in 2013 [34], respectively. Based on the revealed observations, the boundary of the Baishuihe landslide had been determined as the predetermined warning area of the landslide. As shown in Figure 1(b), the morphology of the landslide exhibited an irregular gentle concave shape with the elevation from $120 \mathrm{~m}$ to $297 \mathrm{~m}$ and the volume of $645 \times 10^{4} \mathrm{~m}^{3}$. To date, multiple monitoring devices had been arranged in this typical landslide, involving GPS, borehole clinometer, SNMR, and distributed optical fiber sensor deformation monitoring, as shown in Figure 1(c). The GPS therein was arranged in 2007 by the government, but the monitoring data after 2012 are still unpublicized till now.

3.2. Geological Setting. The Baishuihe landslide is developed in the clastic rocks of the Lower Jurassic Xiangxi Formation
$\left(J_{1 x}\right)$, with the specific lithology of dark gray thin-bedded and medium-bedded siltstone mingling with thin stratified mudstone and coalbed. The inclination direction is $15^{\circ} \sim 20^{\circ}$, coinciding with the main sliding direction. Therefore, the landslide is a monoclinic consequent bedding landslide along the weak intercalated layer initially. However, GPS monitoring data and in situ observations indicated that the deformation is mainly along the formatted sliding zone or the local area of sliding mass rather than along the weak intercalated layer.

According to the drilled holes logs, the slide mass was composed of a soil-rock mixture with the thickness of $7.75 \sim 38.50 \mathrm{~m}$. It comprised various dimensions of subangular siltstone gravels together with silty clay and clay; the gravel content was approximately 10 70\% (Figure 2(a)). There was no unified and continuous layered boundary among the geomaterials. As revealed, the slide zone was composed of subrounded or subangular gravels mixed with silty clay, with an average thickness of $0.7 \mathrm{~m}$. The gravel with the dimension of $1 \sim 6 \mathrm{~cm}$ accounted for a proportion of $20 \sim 30 \%$ in the sliding-zone soil (Figure 2(b)).

According to the drilled holes logs and engineering geological investigation, the representative engineering geological cross section can be plotted, as shown in Figure 3 .

\section{Field-Scale Spatial Variability of $\boldsymbol{K}_{\mathrm{s}}$}

4.1. Interpretation of SNMR Data. There were 15 SNMR survey points arranged in the landslide site in total, which are distributed in 4 survey lines, as shown in Figure 1(c). The SNMR device NUMIS Poly from IRIS Instruments was adopted in this study. The data were measured and interpreted in September 2013 for the spatial variability study and landslide deformation behavior analysis. The built-in procedures of the NUMIS system were applied to address the first-hand surveyed data. After backward extension and noise filtering of the signal, the data can be interpreted using a classic inversion method of least squares based on Tikhonov regularization.

The measured and estimated data for each vertical survey line were not continuous. Therefore, the estimated data with a presupposed interval of $2 \mathrm{~m}$ were set for data extraction. The points of discontinuity were taken into account as well at the same time. As has been measured by the comprehensive field/laboratory tests, the double-ring infiltrometer tests indicated that the $K_{\mathrm{s}}$ values of the landslide surface were within the range of $4.2 \times 10^{-5} \sim 5.0 \times 10^{-4} \mathrm{~cm} / \mathrm{s}$; the borehole water injection tests indicated that the $K_{\mathrm{s}}$ values of the slide mass were within the range of $2.1 \times 10^{-6} \sim 1.4 \times 10^{-4} \mathrm{~cm} / \mathrm{s}$. The laboratory tests indicated that the $K_{\mathrm{s}}$ values of silty clay were within $3.05 \times 10^{-5} \sim 7.12 \times 10^{-5} \mathrm{~cm} / \mathrm{s}$, while for clay, the result was $5.77 \times 10^{-6} \mathrm{~cm} / \mathrm{s}$. According to the aforementioned field measurements, the constant $b^{\prime}$ was calibrated as 4.32 herein. Figure 4 presents the comparison of the lithology indicated by drilled cores together with the surveyed $T_{1}^{*}$ values as well as the estimated $\varnothing$ and $K_{\mathrm{s}}$ values. Notably, we discarded the measured data of the bedrock and slide zone based on the consideration that the research object was the slide mass of the Baishuihe landslide. 


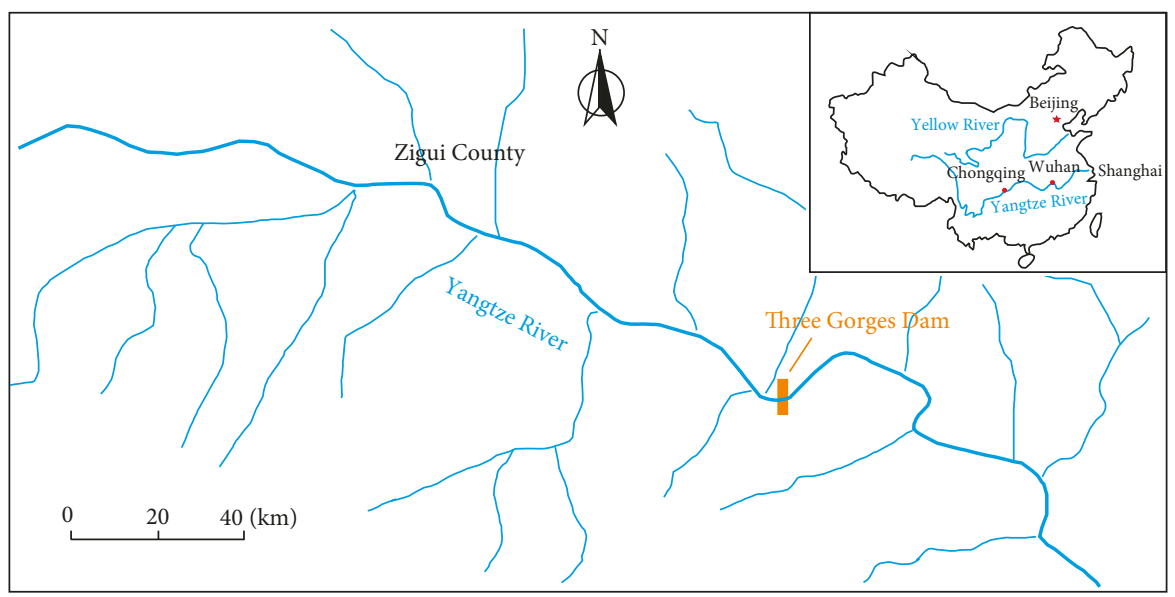

(a)

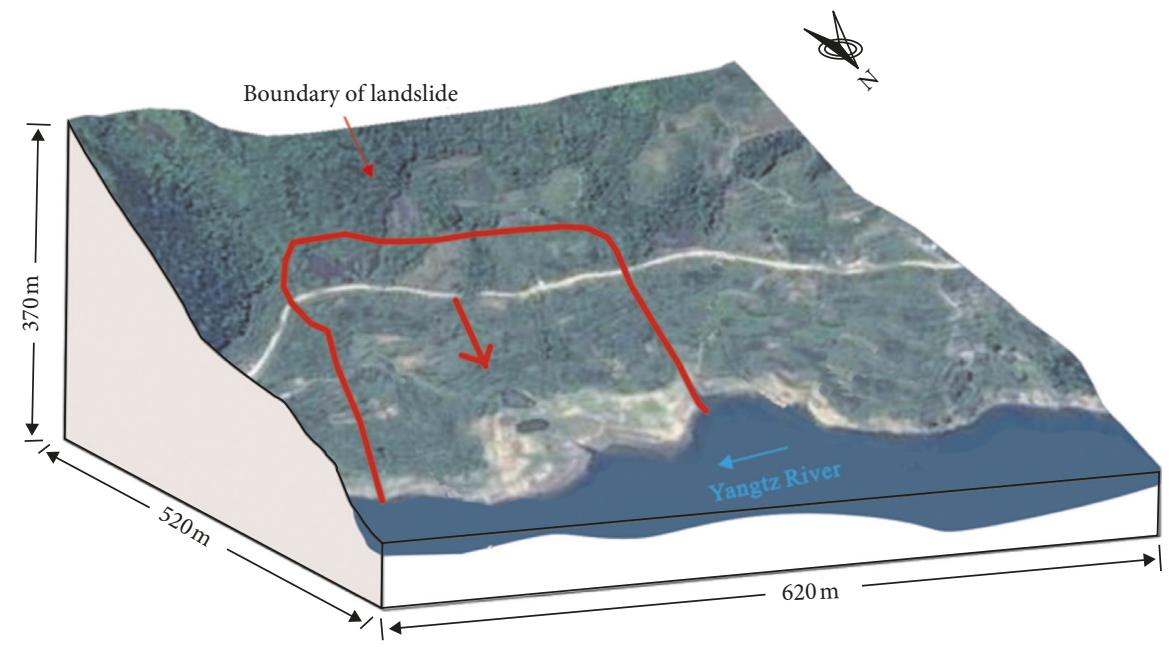

(b)

Figure 1: Continued. 


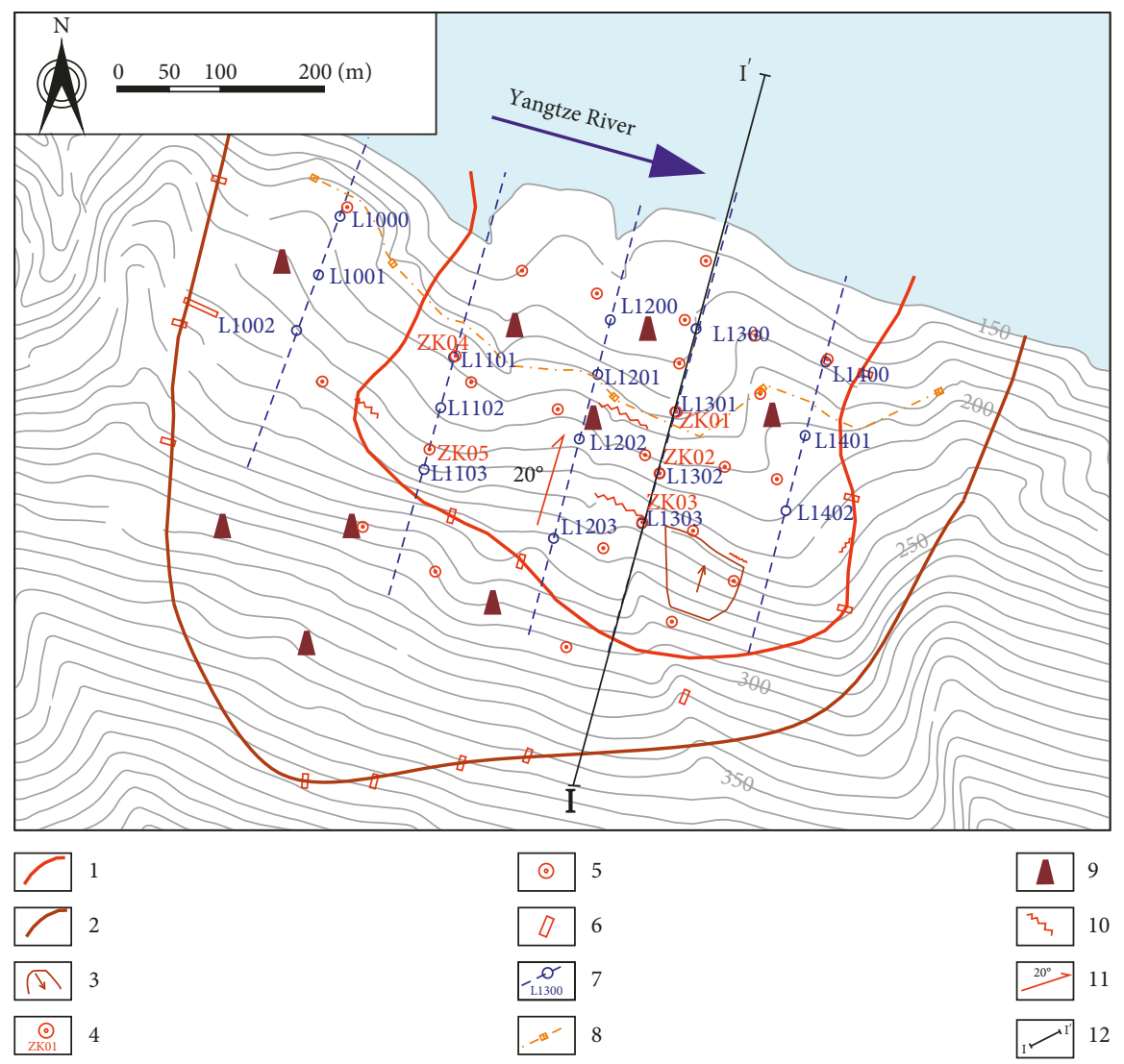

(c)

Figure 1: (a) Location, (b) overview, and (c) planar map of the Baishuihe landslide. (1) Boundary of the landslide based on the engineering geological exploration; (2) the predetermined boundary of the landslide; (3) small collapse; (4) borehole drilled by China University of Geosciences, Wuhan; (5) borehole drilled by Sanxia University; (6) exploratory trench; (7) SNMR survey points and survey line; (8) distributed optical fiber sensor deformation monitoring; (9) GPS monitoring points; (10) ground surface fissures; (11) sliding direction; (12) cross-sectional line.

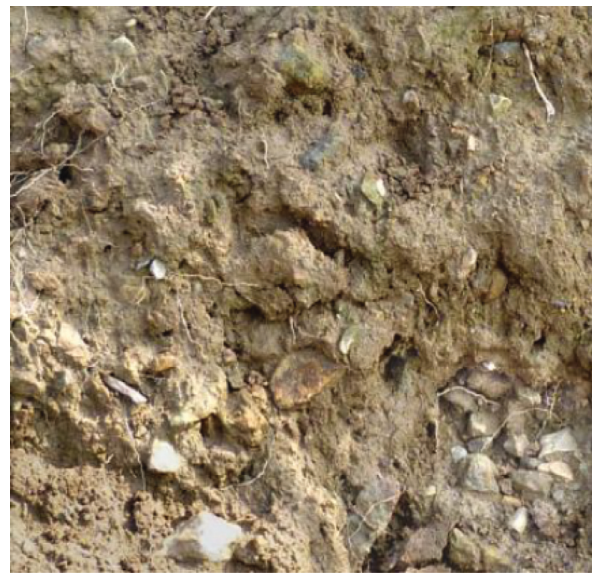

(a)

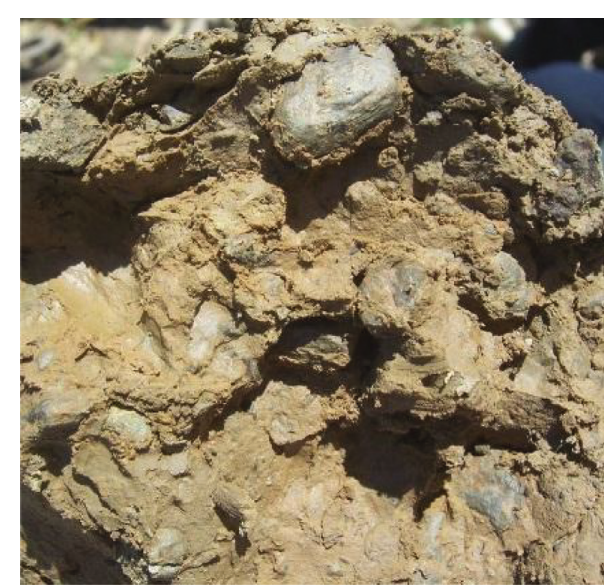

(b)

FIgURE 2: Structure of the geomaterial in the Baishuihe landslide. (a) Colluvial-deluvial deposit soil-rock mixture of the slide mass. (b) Gravel soil of the sliding zone.

4.2. Descriptive Statistics. Descriptive statistics including the overall variability and probability distributions of the estimated parameters of the overall site and major profile
(Figure 2) were discussed. Overall variability can be stated using the maximum, minimum, mean, median, standard deviation (SD), and coefficient of variation $(\mathrm{CV})$ parameters 


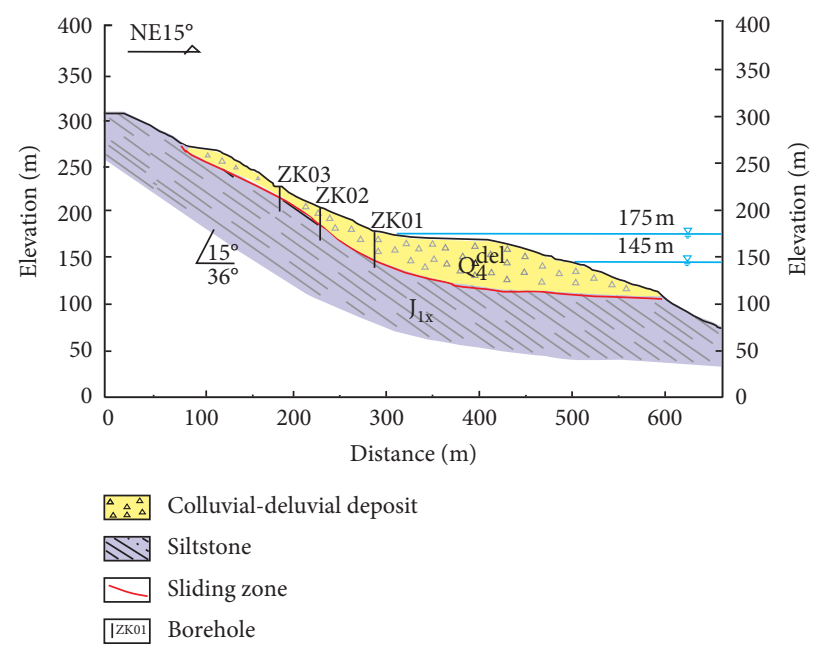

Figure 3: Schematic geological cross section $\left(\mathrm{I}-\mathrm{I}^{\prime}\right)$ of the Baishuihe landslide.

Lithology

Depth

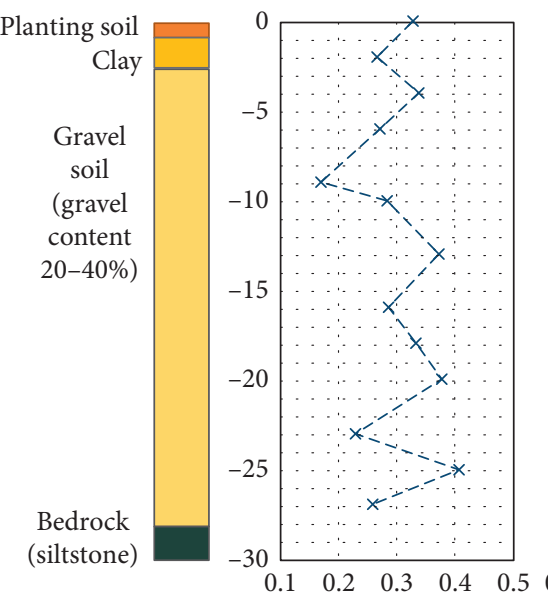

Relaxation time $T_{1}^{*}(\mathrm{~ms})$

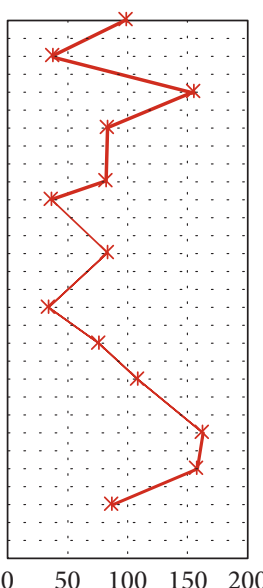

Hydraulic conductivity $K(\mathrm{~cm} / \mathrm{s})$

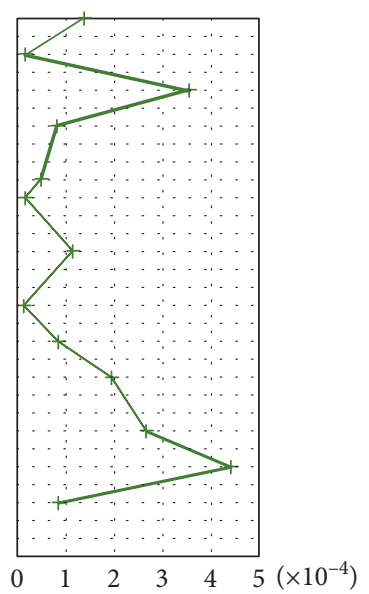

Figure 4: Comparison of drilled core lithology and the SNMR data.

of the estimated data, as shown in Table 1. Notably, the estimated $K_{\mathrm{s}}$ results for the overall landslide site and major cross section had the range between $3.00 \times 10^{-6} \sim 7.80 \times$ $10^{-3} \mathrm{~cm} / \mathrm{s}$ and $4.70 \times 10^{-6} \sim 7.00 \times 10^{-3} \mathrm{~cm} / \mathrm{s}$, which reaches about 3 orders of magnitude. The magnitude of the mean and median values corresponds with the field measurements. The median values were smaller than the mean value for the two analyzed research locations, which reflected the left skewness of the analyzed data. The median value is believed to be more representative generally because it rises superior to the effect of the extreme values compared to the mean value. The $\mathrm{CV}$, a dimensionless parameter of the standard deviation divided by the mean value, representing the degree of variation, was $46 \%$ and $53 \%$ for the overall site and major cross section, respectively. These results implied moderate variability for both the overall site and the major cross section.

With regard to the probability distribution, the frequency histograms of the estimated parameters are shown in Figure 5. As has been exhibited, both of the histograms for $K_{\mathrm{s}}$ for the overall site and the major cross section presented the pattern of left skewness, indicating that the data had a nonnormal distribution. A logarithmic transformation (natural base) was performed on the estimated data for further statistical analysis. As shown in Table 1 and Figure 5, the log-transformed values were normally distributed. Lilliefors tests also indicated that the $K_{\mathrm{s}}$ values for both the overall site and major profile were distributed log normally.

4.3. Spatial Variability Analysis. Geostatistics is a useful tool for analyzing spatial variability and interpolating between point observations [35]. The variogram which describes the spatial variability of $K_{s}$ is a function of the sampling distance under the intrinsic hypothesis of the variable, as shown in the following equation:

$$
\gamma(h)=\frac{1}{2 N(h)} \sum_{i=1}^{N(h)}\left[Z\left(u_{i}\right)-Z\left(u_{i+h}\right)\right]^{2},
$$


TABLE 1: Descriptive statistics for the $K_{\mathrm{s}}$ value of the slide mass of the Baishuihe landslide.

\begin{tabular}{lccccccc}
\hline Location & Number & Maximum & Minimum & Mean & Median & SD & CV \\
\hline Overall site & 169 & $7.00 \times 10^{-3}$ & $3.00 \times 10^{-7}$ & $2.99 \times 10^{-4}$ & $3.20 \times 10^{-5}$ & $8.71 \times 10^{-4}$ & 34 \\
Major profile & 55 & $7.00 \times 10^{-3}$ & $4.70 \times 10^{-6}$ & $6.09 \times 10^{-4}$ & $1.40 \times 10^{-4}$ & $1.35 \times 10^{-3}$ & 45 \\
\hline
\end{tabular}

Note: $K_{\mathrm{s}}$, saturated hydraulic conductivity $(\mathrm{cm} / \mathrm{s})$; $\mathrm{SD}$, standard deviation; $\mathrm{CV}$, coefficient of variation $(\%)$.

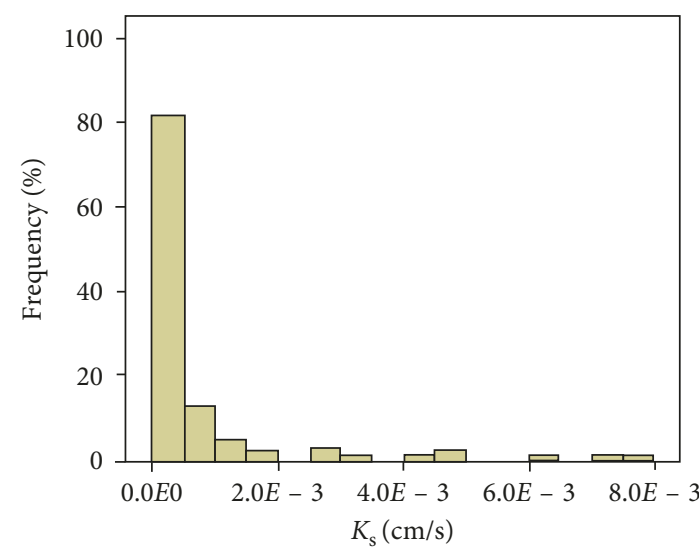

(a)

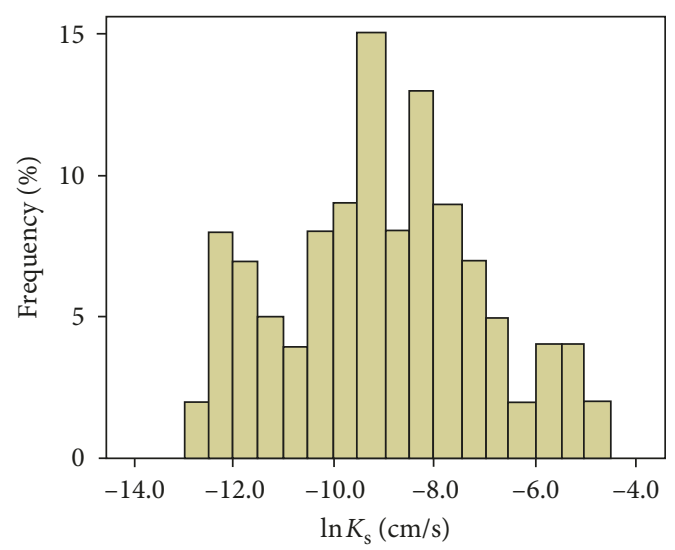

(c)

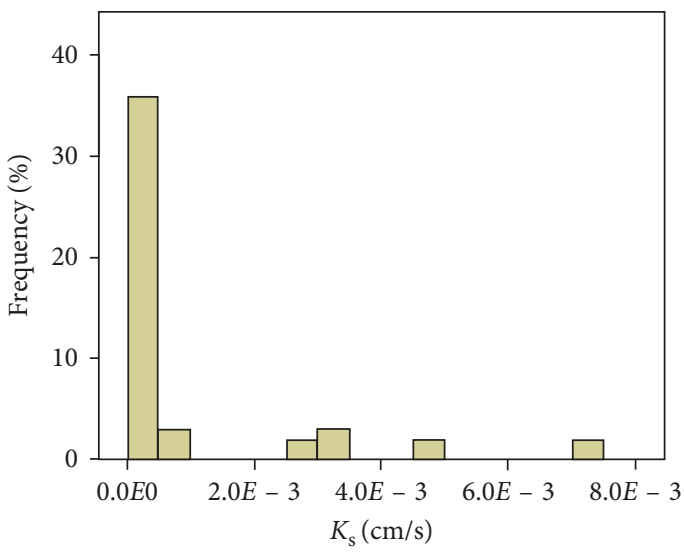

(b)

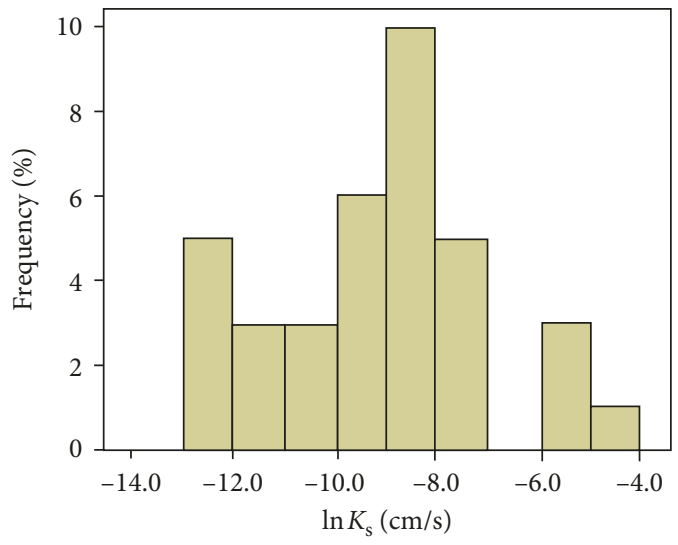

(d)

FIgURE 5: Histograms of the estimated $K_{\mathrm{s}}$ values: (a) $K_{\mathrm{s}}$ for the overall site; (b) $K_{\mathrm{s}}$ for the major cross section; (c) $\ln K_{\mathrm{s}}$ for the overall site; (d) $\ln K_{\mathrm{s}}$ for the major cross section.

where for each site $i, Z\left(u_{i}\right)$ and $Z\left(u_{i+h}\right)$ are values of $Z$ at locations $u_{i}$ and $u_{i+h}$, respectively; $h$ is the lag; and $N(h)$ is the number of pairs of sample points separated by $h$. The value of $\gamma\left(h_{i}\right)$ at a different separation distance $h_{i}$ can be calculated in terms of Equation (4). Therefore, the calculated $\left[h_{i}, \gamma\left(h_{i}\right)\right]$ points constitute experimental variograms. The variogram describes the spatial variability in terms of 3 representative parameters. The nugget $\left(C_{0}\right)$ represents the variability induced by microheterogeneity and experimental error, which occurs at distances smaller than the sampling intervals. The sill $\left(C_{0}+C\right)$ represents the total variance of the variable, and the range $(A)$ represents the action range of the spatial correlation. The value of $\gamma(h)$ would not increase but fluctuates around $C_{0}+C$ when the separation distance reaches $A$ [36]. The theoretical variogram models (i.e., exponential model, spherical model, Gaussian model, etc.) are employed to fit the calculated experimental variograms. The best-fitted theoretical models indicated by the greatest coefficient of correlation $(R)$ and the least residual sum of squares (RSS) can be undertaken to represent the experimental variograms.

In this study, we investigated the omnidirectional spatial variable patterns for $\ln K_{\mathrm{s}}$ values of the overall site and major profile because of the insufficient data pairs along some characteristic directions. The scale effect caused by the different data intervals along vertical and horizontal directions was also taken into consideration by calculating different experimental variograms, which was characterized by small-scale variograms and large-scale variograms, respectively.

The calculated experimental variograms and the modeled theoretical variograms fitted by the exponential model, 
spherical model, and Gaussian model are shown in Figure 6. The corresponding fitting parameters for the 3 models are listed in Table 2. It is noticeable that $a$ was the fitting parameter which equaled to $A$ for the spherical model, while it equaled to $3 a$ and $\sqrt{3} a$ for exponential and Gaussian models, respectively. A greater $A$ represents a greater range of variable regular changes and greater spatial correlation [37]. The greatest $R$ and the least RSS indicated the best fit model for $\ln K_{s}$, i.e., $K_{\mathrm{s}}$. For the overall site study, the exponential model provided the best fit for the small-scale study because of the least RSS and the slight difference among the three models, while the spherical model provided the best fit for the large-scale study. For the major cross section, the spatial variation for a small-scale study was insignificant and the spherical model provided the best fit for a large-scale study. According to the fitting parameters, the (nested) variogram functions can be deduced for representing the variogram structure [34]. The variogram function for $\ln K_{\mathrm{s}}$ of the overall site and major profile can be deduced as follows.

Overall site:

$$
\gamma(h)= \begin{cases}1.5, & h=0, \\ 2.5-e^{-(h / 2.83)}+4.9\left(\frac{3}{2} \cdot \frac{h}{295.89}-\frac{1}{2} \cdot \frac{h^{3}}{295.89^{3}}\right), & 0<h \leq 295.89, \\ 7.4, & h>295.89 .\end{cases}
$$

Major profile:

$$
\gamma(h)= \begin{cases}0.58, & h=0, \\ 0.58+2.96\left(\frac{3}{2} \cdot \frac{h}{65.56}-\frac{1}{2} \cdot \frac{h^{3}}{65.56^{3}}\right), & 0<h \leq 65.56 \\ 3.54, & h>65.56 .\end{cases}
$$

Equations (5) and (6) indicated that the studied variables (ln $K_{\mathrm{s}}$ values) were spatially correlated within $A$ of the largescale study. The $A$ values reached $295.89 \mathrm{~m}$ and $65.56 \mathrm{~m}$, respectively, for the overall site and major cross section, which suggested that the investigated spatial variation was remarkably dependent on the research direction. The directional variogram structure can be investigated in the further studies in terms of more comprehensive measurements and estimations. Meanwhile, the effect of small-scale spatial variability contributed significantly to the nugget and sill, which represents the randomness derived from the microstructure and errors as well as the variable variation degree within the studied range.

The nugget-to-sill ratio (NSR) was employed to define the degree of spatial dependency. The greater the NSR value, the greater the variation degree caused by randomness. A low NSR value $(<25 \%)$ indicates a strong spatial dependence of the variables under the strong impact of structural factors. A higher NSR value (25\% 75\%) indicates a moderately spatial variable dependence. If it is higher than $75 \%$, the variable is of weak spatial dependence, and randomness plays an important role $[11,38]$. As shown in Table 2, all NSR values (except for the NSR of $\ln K_{s}$ for the overall site with a small scale) were lower than $25 \%$, suggesting that the spatial variation of $K_{\mathrm{s}}$ is mainly dependent on the deposit structure. The $K_{\mathrm{s}}$ for the overall site with a small scale depended on structural factors and randomness.

\section{Deformation Behavior Analysis Based on Spatial Variable $K_{\mathrm{s}}$}

5.1. Analyzing Method and Calculation Model. A 2D deformation behavior analysis of the major profile associated with the spatial variable $K_{\mathrm{s}}$ value under the combined effect of reservoir water fluctuation and rainfall has been carried out in this study. The commercial finite-element code SEEP/W (by Geoslope International Ltd.) [39], which is capable of solving finite-element equations for the steadystate flow governed by Darcy's law and for transient flow under the hypothesis of Terzaghi-Rendulic uncoupled consolidation, was used herein.

An ordinary Kriging estimation method was then applied to the orthogonal structural grids $(4 \mathrm{~m} \times 4 \mathrm{~m})$ subjected to the geometry of the slide mass on the basis of conditional spatial data (SNMR-measured $K_{\mathrm{s}}$ ) and a covariance matrix derived from the variogram structure analyzed in the aforementioned section. The method is believed to provide the best unbiased linear estimation for the unknown points $[36,37]$ using a system equation:

$$
\begin{aligned}
& {\left[\begin{array}{ll}
\mathbf{K} & \mathbf{I} \\
\mathbf{I}^{T} & 0
\end{array}\right]\left[\begin{array}{l}
\boldsymbol{\beta} \\
\lambda
\end{array}\right] }=\left[\begin{array}{l}
\mathbf{k} \\
1
\end{array}\right], \\
& \mathbf{K}=\left[\begin{array}{cccc}
K_{11} & K_{12} & \cdots & K_{1 p} \\
K_{21} & K_{22} & \cdots & K_{2 p} \\
\vdots & \vdots & \cdots & \vdots \\
K_{p 1} & K_{p 2} & \cdots & K_{p p}
\end{array}\right], \\
& \boldsymbol{\beta}=\left[\begin{array}{cccc}
\beta_{1} & \beta_{2} & \cdots & \beta_{p}
\end{array}\right]^{T}, \\
& \mathbf{k}=\left[\begin{array}{llll}
K_{i 1} & K_{i 2} & \cdots & K_{i p}
\end{array}\right]^{T}, \\
&\left(i=\left[1, n_{e}\right] \text { and } i \neq 1,2, \ldots, p\right),
\end{aligned}
$$

where $\mathbf{K}$ is the covariance matrix; $\mathbf{I}$ is a column vector of all points with a length of $p ; \boldsymbol{\beta}$ is the vector of weights of the known data with $\sum_{i=1}^{p} \beta_{i}=1$; $\mathbf{k}$ is the vector of covariance between the estimated points and known points; and $\lambda$ is a Lagrange multiplier. As shown in Figure 7, the variation range of the $K_{\mathrm{s}}$ values transformed from the interpolated $\ln K_{\mathrm{s}}$ values of the research domain was $1.37 \times 10^{-6} \sim 1.11 \times$ $10^{-2} \mathrm{~cm} / \mathrm{s}$, which coincided with the laboratory and field measurements.

The calculation model was generated in SEEP/W. As shown in Figure 8, the mesh element of the slide mass had the same specification with the estimation grid. There were 1968 nodes in total and 1970 elements available in this calculation model. The $K_{\mathrm{s}}$ value of each element of the slide mass can be assigned individually by rewriting the XML file 


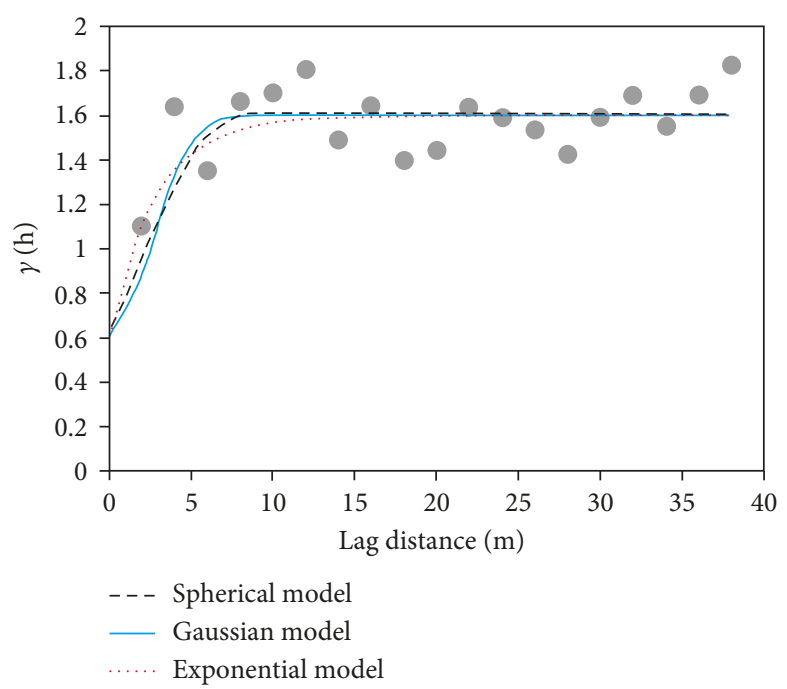

(a)

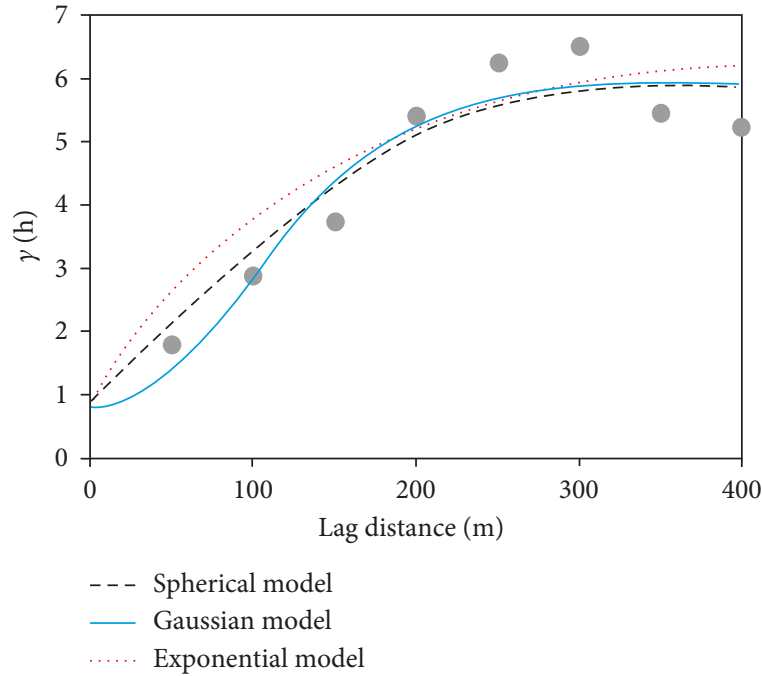

(b)

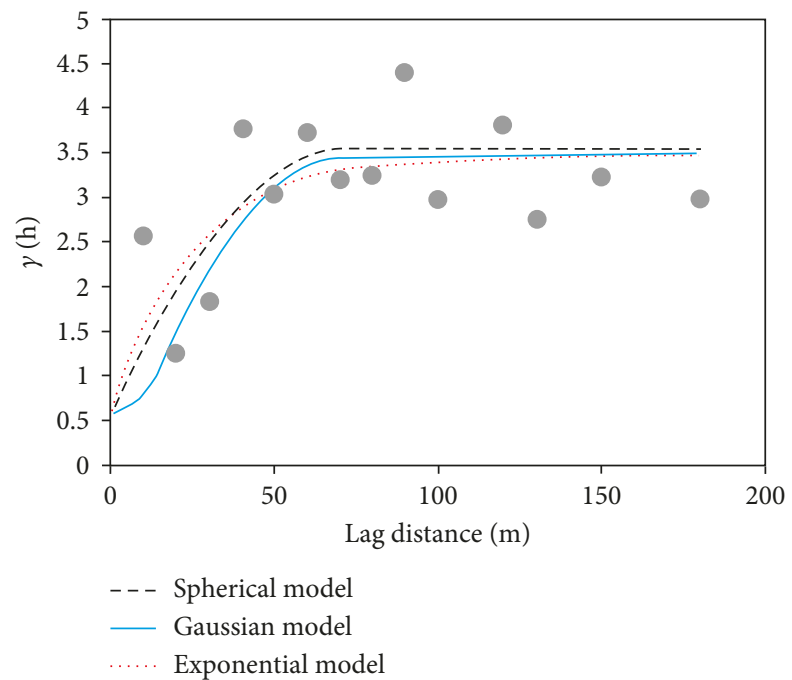

(c)

FIGURE 6: Omnidirectional variograms of the estimated $\ln K_{\mathrm{s}}$ values: (a) the small-scale variogram for ln $K_{\mathrm{s}}$ for the overall site; (b) the largescale variogram for $\ln K_{\mathrm{s}}$ for the overall site; (c) the large-scale variogram for $\ln K_{\mathrm{s}}$ for the major cross section.

TABLE 2: Parameters of fitting theoretical variogram models for the $\ln K_{\mathrm{s}}$ value.

\begin{tabular}{lccccccccc}
\hline Study site & Study scale & Theoretical model & $a(\mathrm{~m})$ & $A(\mathrm{~m})$ & $C_{0}$ & $C+C_{0}$ & NSR $(\%)$ & $R$ \\
\hline \multirow{4}{*}{ Overall site } & Small & Spherical & 8.12 & 8.12 & 0.60 & 1.60 & 37.50 & 0.5956 & 0.4174 \\
& & Exponential & $\mathbf{2 . 8 3}$ & $\mathbf{8 . 4 9}$ & $\mathbf{0 . 6 0}$ & $\mathbf{1 . 6 0}$ & $\mathbf{3 7 . 5 0}$ & $\mathbf{0 . 5 9 5 9}$ & $\mathbf{0 . 3 6 2 0}$ \\
& & Gaussian & 3.51 & 6.08 & 0.60 & 1.60 & 37.50 & 0.6121 & 0.4307 \\
& \multirow{4}{*}{ Large } & Spherical & $\mathbf{2 9 5 . 8 9}$ & $\mathbf{2 9 5 . 8 9}$ & $\mathbf{0 . 9 0}$ & $\mathbf{5 . 8 0}$ & $\mathbf{1 5 . 5 2}$ & $\mathbf{0 . 9 7 8 7}$ & $\mathbf{1 . 7 2 9 1}$ \\
& & Exponential & 134.50 & 403.50 & 0.80 & 6.50 & 12.31 & 0.9228 & 4.3707 \\
& & Gaussian & 138.30 & 239.54 & 0.80 & 5.10 & 15.69 & 0.9530 & 1.8442 \\
\hline \multirow{3}{*}{ Major profile } & \multirow{3}{*}{ Large } & Spherical & $\mathbf{6 5 . 5 6}$ & $\mathbf{6 5 . 5 6}$ & $\mathbf{0 . 5 8}$ & $\mathbf{3 . 5 4}$ & $\mathbf{1 6 . 3 8}$ & $\mathbf{0 . 6 4 7 9}$ & $\mathbf{5 . 5 4 8}$ \\
& & Exponential & 24.83 & 74.49 & 0.55 & 3.56 & 15.45 & 0.5970 & 5.572 \\
& & Gaussian & 33.98 & 58.85 & 0.56 & 3.58 & 15.64 & 0.6620 & 6.446 \\
\hline
\end{tabular}

Note: NSR, nugget-to-sill ratio; $R$, coefficient of correlation; RSS, residual sum of squares; the best-fit theoretical model is marked in bold.

of SEEP/W. The front of the slope related to the reservoir water level, while the surface above the water level was assigned as a rainfall boundary with variable precipitation.
The back edge was assigned a constant water head of $240 \mathrm{~m}$, while the bottom was assigned as a zero-flux boundary. The SIGMA/W code was subsequently utilized for analyzing the 


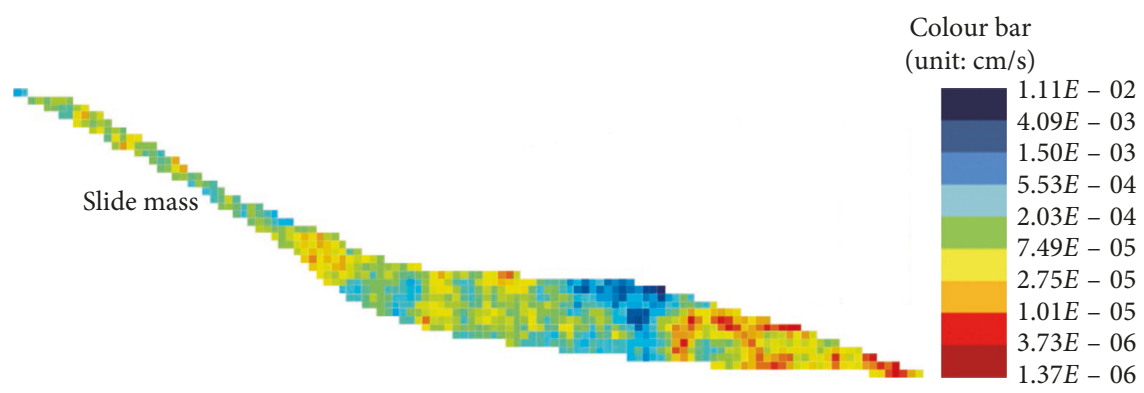

Figure 7: Estimated $K_{\mathrm{s}}$ value of the slide mass based on the ordinary Kriging interpolation method.

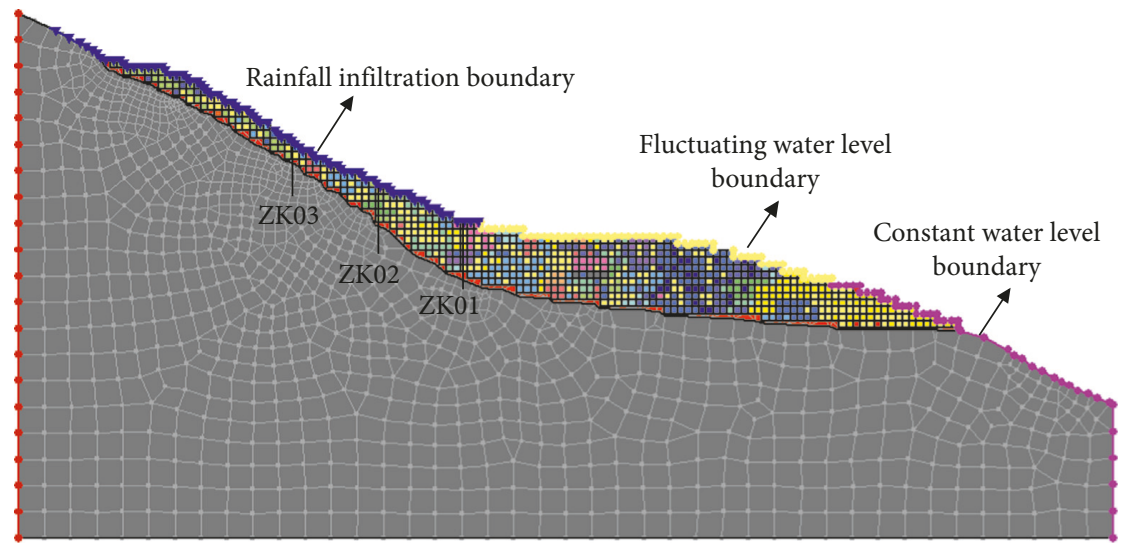

FIGURE 8: Meshed elements and presupposed boundary condition of the calculation model in SEEP/W.

deformation behavior associated with the seepage field results.

According to the laboratory experimental measurements and engineering geologic analogy method, the adopted calculation parameters are shown in Table 3. Apart from $K_{\mathrm{s}}$ values of the slide mass, the other parameters for the landslide were identified as a single variable. The volumetric water content function for the slide zone was estimated on the basis of laboratory experimental results, of which $\alpha=$ $0.029 \mathrm{kPa}^{-1}, n=1.24, \theta_{\mathrm{r}}=0.103$, and $\theta_{\mathrm{s}}=0.315$, while the volumetric water content function for the slide mass was estimated on the basis of the grain size distribution and the estimated $K_{\mathrm{s}}$ according to the modified Kovacs method [40].

Three inclinometer holes were arranged in this major profile corresponding to $\mathrm{ZK} 01, \mathrm{ZK} 02$, and $\mathrm{ZK} 03$, as shown in Figure 8. However, two of the three inclinometer tubes had been destroyed because of undetermined reasons. Therefore, ZK01 was the remaining inclinometer hole for in-depth displacement monitoring. The actual daily rainfall precipitation and reservoir water level of the exact monitoring period, from December 28, 2013, to October 20, 2014, were selected as the calculation condition for seepage and deformation behavior analysis.

5.2. Results and Comparison. The simulated seepage and deformation behavior for 4 sections (as shown in Figure 9) were investigated in this study, including the three sections (S1, S2, and S3) corresponding to the drilled holes with inclinometers of ZK03, ZK02, and ZK01, respectively, as well as $S 4$ representing the unavailable bottom section beneath the water level. The horizontal cumulative displacement time history of the surfaces of the 4 studied sections are presented in Figure 10 to compare with the outer condition of rainfall and fluctuating water level. A significant deformation was detected at the bottom of the landslide (S4) at the very beginning under the condition of reduction of the reservoir water level. However, the displacement sustained at approximately $200 \mathrm{~mm}$ from January to July 2014 until a heavy rainstorm occurred in August 7 and facilitated the deformation under the combinational effect of reservoir water storage. The time history of S4 indicates that the deformation of the front of the landslide is sensitive to both fluctuating water level and rainfall. However, the upper sections of the landslide (S1-S3) produced negligible deformation during the entire simulation period relatively, which indicates that the deformation of the landslide is progressive. The onset of the deformation of S1-S3 was initially facilitated by an expedited drawdown of the water level and relatively intense rainfall. The step-like displacement was re-onset by the intensive rainfall in July and August of that year. The deformation for S2 and S3 increased drastically after a remarkable heavy rainfall on August 7, 2014, and lasted for two months after the remarkable rainfall was associated with the increasing water level. Miao et al. also proposed that the displacement of the Baishuihe landslide changed stepwise at the rainfall-concentrated months from May to October of every year through a multiyear displacement analysis [33]. 
TABLE 3: Parameters of the calculation model.

\begin{tabular}{lccccc}
\hline Component & $\gamma\left(\mathrm{kN} / \mathrm{m}^{3}\right)$ & $K_{\mathrm{s}}(\mathrm{cm} / \mathrm{s})$ & $C(\mathrm{kPa})$ & $\phi\left(^{\circ}\right)$ & $E(\mathrm{~Pa})$ \\
\hline Slide mass & 20.7 & - & 18.62 & 17 & $7.90 \times 10^{7}$ \\
Slide zone & 20 & $3.37 \times 10^{-6}$ & 26.1 & 15.5 & $1.22 \times 10^{7}$ \\
Bedrock & 24.8 & $1.21 \times 10^{-8}$ & 228 & 34.2 & 0.31 \\
\hline
\end{tabular}

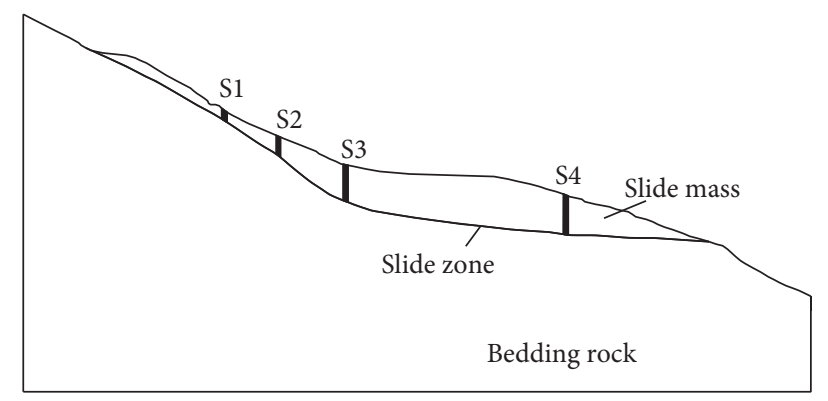

S1 I Monitoring section

FIGURE 9: Monitored sections' sketch of numerical simulation.

The multiyear displacement monitoring data also indicated that the landslide has cumulated a spectacular displacement (approximately 1 2 $\mathrm{m}$ ) at the intermediate section by stages since the first impoundment of the Three Gorges Reservoir in 2007, but it remains stable [30-33] because of the toe resistance result from the gentle slope of the interface of the sliding mass and the bedrock.

During the simulation period, five representative points in time were selected to evaluate the seepage and deformation processes, as illustrated in Table 4. The simulated pore water pressure and displacement profile of the investigated points in time along the 4 sections were extracted from the numerical simulation, as presented in Figure 11. As indicated by Figures 11(a)-11(c), the stable depth of the zero-pore water pressure implying the embedded water table during the entire simulation period suggests that the water level and rainfall have little impact on the underlying water table at the upper and intermediate sections. However, the water table at the toe section varies remarkably in close relation to the fluctuating water level and rainfall (Figure 11(d)). The pore water pressure profiles above the bedrock for S1, S2, and S3 present a convoluted pattern with a negative value, indicating that the suction is greatly dependent on the daily rainfall at the upper section of the landslide.

As suction dissipated in the slide mass above the bedrock because of the rainfall, the kinematics of the landslide deformation changed with progressive movement in the geomaterials. The deformation of the top section ( $\mathrm{S} 1$, as in Figure 11(e)) presents the pattern of greatest displacement at the surface dissipating along with the depth, without drastically changing at the sliding zone, which is implicative of a superficial deformation. The simulated displacement of the surface of $\mathrm{S} 1$ reached the peak value $(58.40 \mathrm{~mm})$ on October 72014 after a heavy storm, and the subsequent deformation was negligible. The deformation for S2 and S3 followed a translational mechanism, represented by relative uniform displacements above the sliding zone (Figures 11(f) and $11(\mathrm{~g}))$. The in-field-monitored depth-displacement profile for S3 (ZK01) is also exhibited in Figure 11(g). The monitored displacement deflected at the depth of $28 \mathrm{~m}$ beneath the ground surface, corresponding to the depth of the sliding zone. Such commensurate patterns with the simulated displacement curve demonstrate the reliability of the numerical results. Relatively, the displacement of the toe (S4) exhibits a distinct pattern that is tortuous with a great rotation at the depth of $8 \mathrm{~m}$ for the entire investigated period, which is implicative of a secondary sliding surface located in this depth at the toe. The deformation of S4 was significant from the very beginning and maintained its stability until October 2014, which is implicative of the great effect of the heavy rainfall and fluctuating water level.

According to the field investigation on October 202014 , the Baishuihe landslide has produced remarkable crack in the middle platform (Figure 12(a)) and shallow collapse of the back edge (Figure 12(b)). The inclinometer PVC tubes located in ZK02 and ZK03 were discovered to have been destroyed at the depth of less than $1 \mathrm{~m}$. The distributed optical fiber sensor arranged at the front of the landslide was discovered to be pulled apart as well. However, the exact time of occurrence of the great deformation is not verifiable. The newly outcropped large crack and collapse suggested that the deformation was not occurring for a long time, no more than 2 months. It is noticeable that the maximum simulated displacement for ZK02 and ZK03 (59.84 $\mathrm{mm}$ and $31.39 \mathrm{~mm}$ ) was not large enough for the complete damage of the inclinometer pipes in general. The reason lies on the shallow deformation along the weaker zone (not sliding zone) due to the complex effects of vegetation cover, development of tension cracks, erosion, etc. The shallow deformation is also difficult to be captured during the numerical simulation.

All of the field observations and simulated results provided insights into the complex deformation behavior of the 


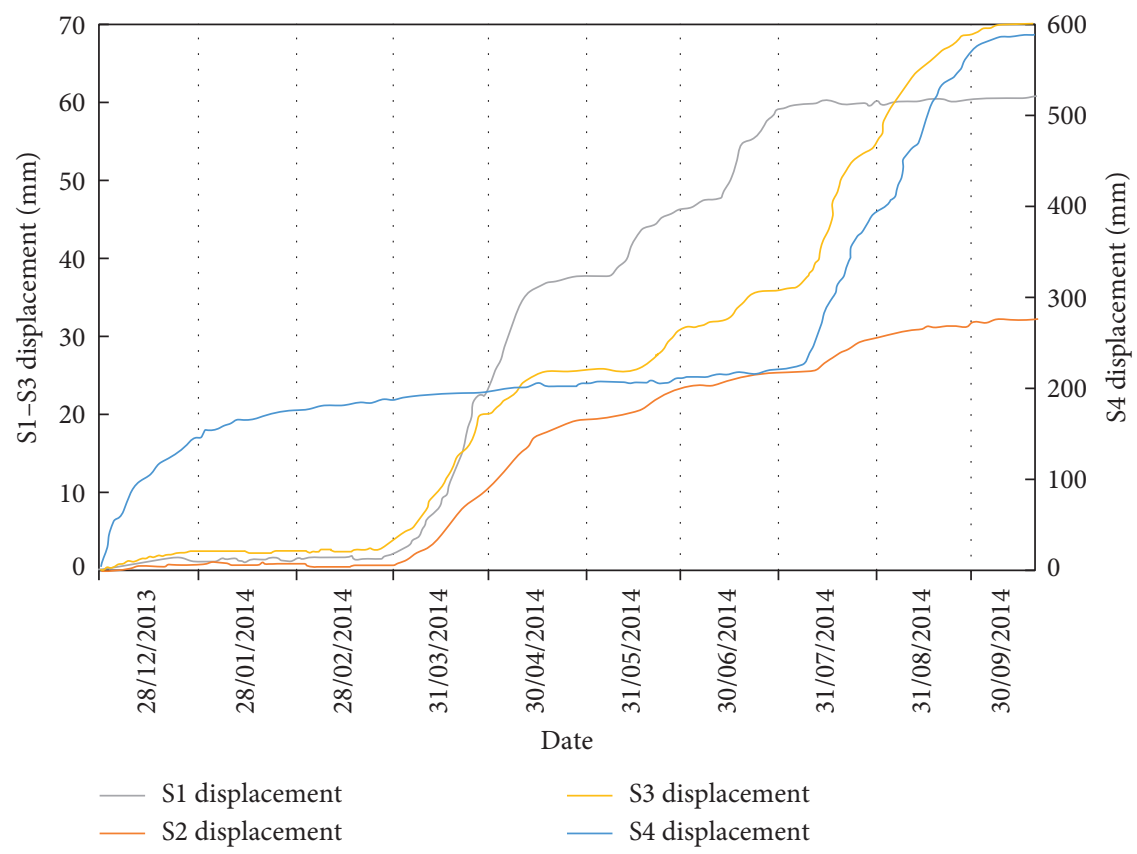

(a)

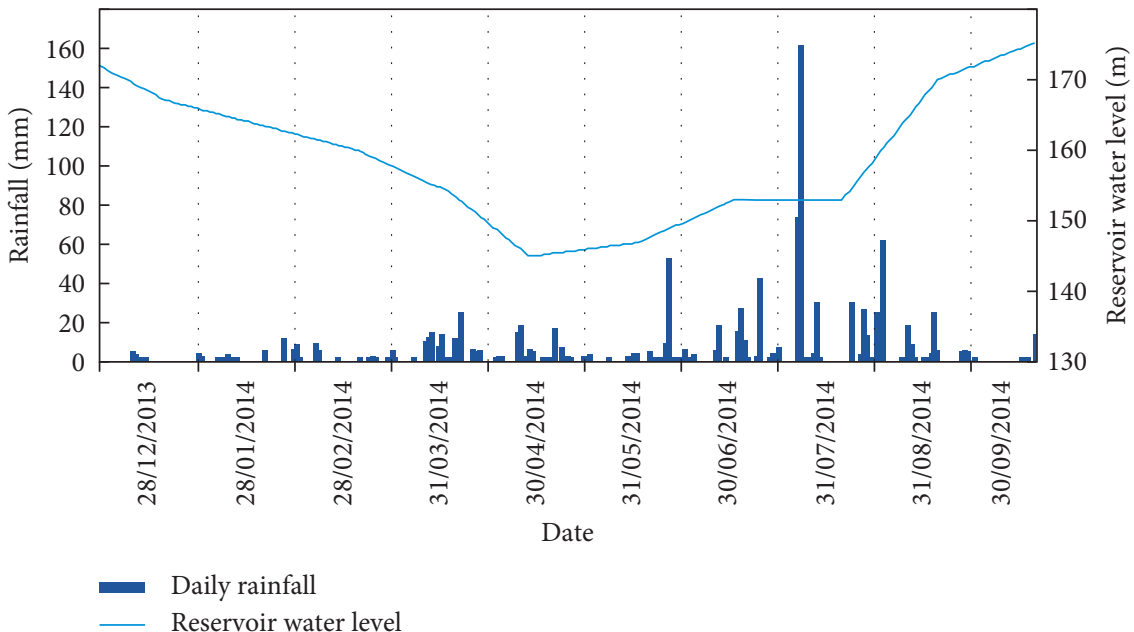

(b)

Figure 10: Surface displacement (a) and daily rainfall and reservoir water level (b) from December 28, 2013, to October $20,2014$.

Baishuihe landslide. The deformation behavior is progressive, occurring initially at the front of the landslide and progressing backwards. The deformation is greatly influenced by rainfall and reservoir water fluctuation. When the reservoir water level drops, a hydraulic gradient is produced due to the quick decrease of the water level compared to that of the groundwater table and it exerts an adverse effect on the landslide stability. When the reservoir stores water, the groundwater table level lifts gradually, thus increasing the weight of the geomaterial beneath the water table and softening the material. The pore water pressure in the slide mass and the sliding zone increases simultaneously; thus, the effective stress of the geomaterial beneath the water table decreases and produces deformation. In the case of heavy rain, the infiltration of the rain decreases the suction of the slide mass and thus decreases the effective stress. Besides, the heavy rainfall produces surface runoff and causes the erosion of the landslide surface, which exacerbates the deformation of the surface. Consequently, the reservoir water impoundment and heavy rainfall are the most important factors that affect the Baishuihe landslide deformation.

\section{Conclusions}

The presented case study described the spatial variability of $K_{\mathrm{s}}$ values of a representative accumulation reservoir landslide in TGRA, China, estimated by the SNMR survey work arranged in the landslide field. The finite-element seepagestress simulation results based on the spatially variable $K_{\mathrm{s}}$ values provided insights into the deformation behavior of 
TABLE 4: Representative points in time and description.

\begin{tabular}{lccccc}
\hline Date & Days & Rainfall $(\mathrm{mm})$ & Water level $(\mathrm{m})$ & Inclinometer monitoring & Description \\
\hline December 28, 2013 & 1 & 0 & 174 & $\sqrt{ }$ & High water level \\
March 27, 2014 & 90 & 0.8 & 158 & - & Water level drawdown \\
June 6, 2014 & 161 & 0 & 146 & - & Low water level \\
August 7, 2014 & 223 & 160.7 & 153 & $\sqrt{ }$ & Low water level with very heavy daily rainfall \\
October 20, 2014 & 297 & 13.2 & 175 & High water level \\
\hline
\end{tabular}

Note: $\sqrt{ }$ means having inclinometer monitoring data for comparison.

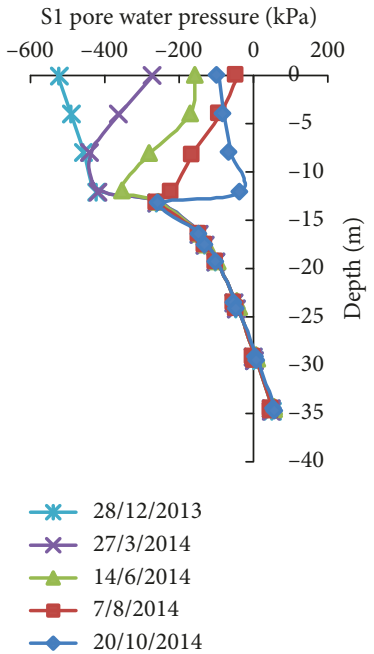

(a)

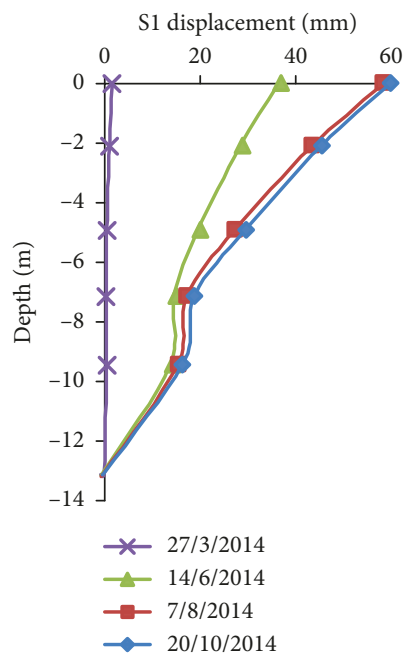

(e)
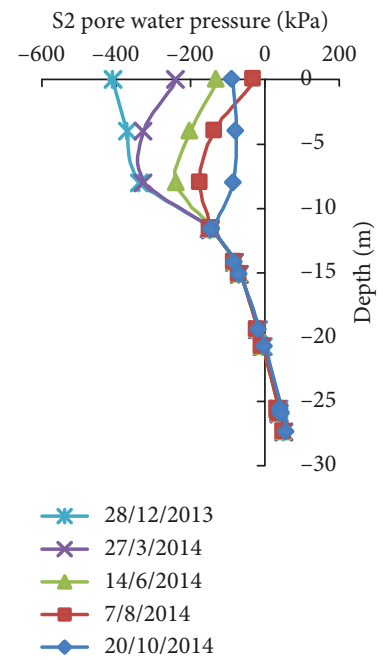

(b)

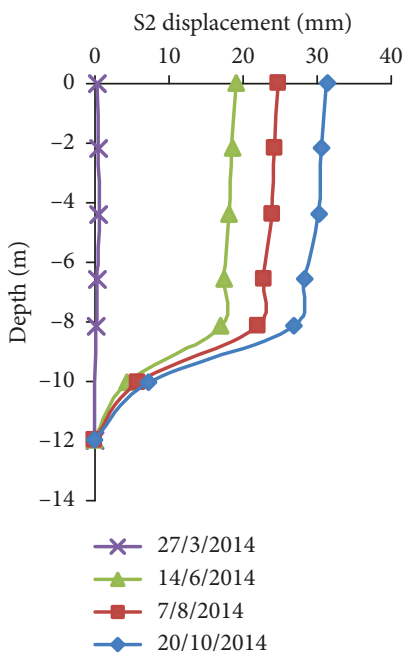

(f)
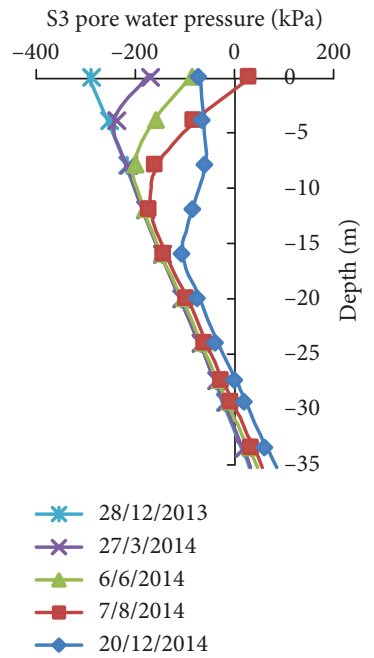

(c)

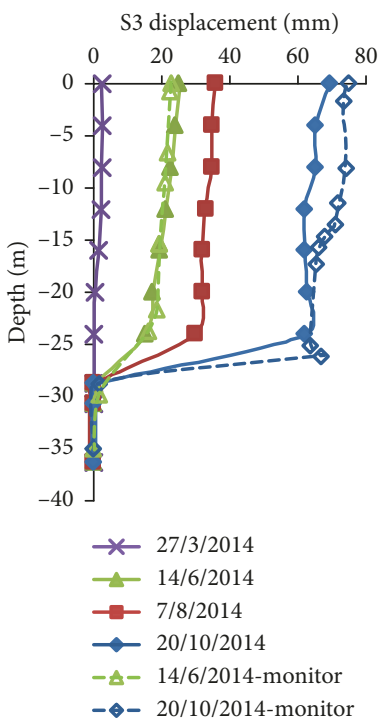

(g)

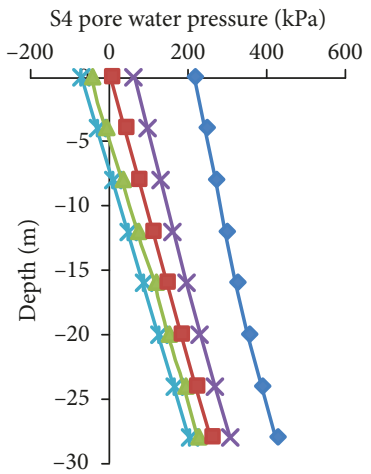

$\approx$ 28/12/2013
$-27 / 3 / 2014$
$\leftarrow$ 14/6/2014
$-\quad 7 / 8 / 2014$
$\simeq \quad 20 / 10 / 2014$

(d)

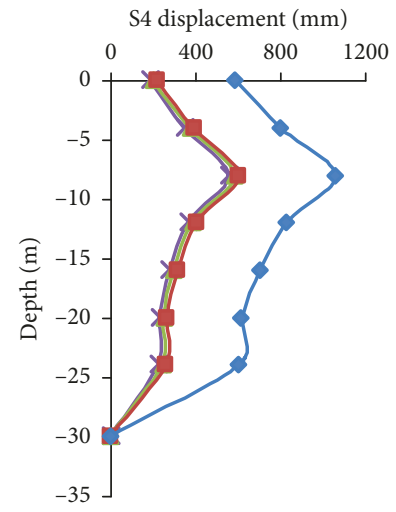

$$
\begin{aligned}
& \leftarrow \text { 27/3/2014 } \\
& -14 / 6 / 2014 \\
& \rightarrow-7 / 8 / 2014 \\
& \rightarrow-20 / 10 / 2014
\end{aligned}
$$

(h)

FIgURE 11: Simulated pore water pressure and displacement over time along sections of the Baishuihe landslide.

the landslide associated with the in-field observations. The conclusions from the study are as follows:

(1) The SNMR technology provides a strategy for obtaining a series of relatively reliable spatial measurements of hydrological parameters of landslide fields using a noninvasive method. The estimation should be calibrated according to the field tests measurements.

(2) The estimated $K_{\mathrm{s}}$ values for the overall landslide mass site are log-normally distributed within a wide range between $3.00 \times 10^{-6} \mathrm{~cm} / \mathrm{s}$ and $7.80 \times 10^{-3} \mathrm{~cm} / \mathrm{s}$ and are associated with the $\mathrm{CV}$ of $34 \%$. The variogram 


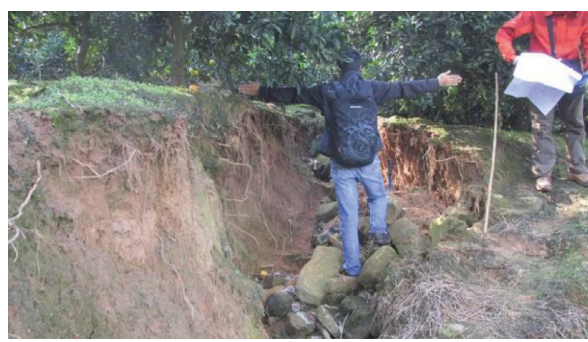

(a)

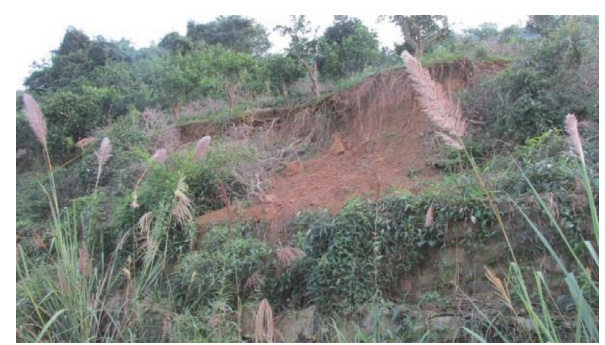

(b)

Figure 12: Large deformation observations in the Baishuihe landslide site. (a) Great fissure at the intermediate platform. (b) Small collapse at the top section of the landslide.

analysis considering the scale effect caused by the different data intervals along different directions shows that the nested variogram has $A$ of $298.89 \mathrm{~m}$ and $65.56 \mathrm{~m}$, respectively, for the overall site and major cross-sectional analysis. The spatial variation of $K_{\mathrm{s}}$ is mainly dependent on the structure of the deposit.

(3) The displacement time history as well as the pore water pressure and displacement of the studied sections based on the finite-element seepage-stress analysis of a Kriging-interpolated spatial variable $K_{\mathrm{s}}$ value calculation model provide important insights into the deformation behavior of the landslide associated with the in-field observations and monitoring data. All of the results indicate that the Baishuihe landslide is a progressive landslide with significant secondary sliding at the front section and superficial deformation at the back section. The available information indicates the main factor influencing the landslide deformation is rainfall and reservoir water fluctuation.

This study provides an unconventional framework for studying the heterogeneous geomaterial and contributes to a better understanding of the spatial variability of the hydraulic property of accumulation reservoir landslides at a field scale.

\section{Data Availability}

The data used to support the findings of this study are available from the corresponding author upon request.

\section{Conflicts of Interest}

The authors declare that there are no conflicts of interest regarding the publication of this article.

\section{Acknowledgments}

This research was supported by the National Key R\&D Program of China (No. 2017YFC1501304), the China Postdoctoral Science Foundation (No. 2016M592411), and the National Natural Science Foundation of China (Nos. 41572279, 41807271, and 41877259).

\section{References}

[1] J. E. Wang, W. Xiang, and L. Ning, "Landsliding triggered by reservoir operation: a general conceptual model with a case study at Three Gorges Reservoir," Acta Geotechnica, vol. 9, no. 5, pp. 771-788, 2014.

[2] H. M. Tang, C. D. Li, X. L. Hu et al., "Deformation response of the Huangtupo landslide to rainfall and the changing levels of the Three Gorges Reservoir," Bulletin of Engineering Geology and the Environment, vol. 74, no. 3, pp. 933-942, 2015.

[3] A. Perrone, R. Vassallo, V. Lapenna, and D. M. Caterina, "Pore water pressure and slope stability: a joint geophysical and geotechnical analysis," Journal of Geophysics and Engineering, vol. 5, no. 3, pp. 323-337, 2008.

[4] Q. Zhai and H. Rahardjo, "Estimation of permeability function from the soil-water characteristic curve," Engineering Geology, vol. 199, pp. 148-156, 2015.

[5] H. Q. Dou, T. C. Han, X. N. Gong, Z. Y. Qiu, and Z. N. Li, "Effects of the spatial variability of permeability on rainfallinduced landslides," Engineering Geology, vol. 192, pp. 92-100, 2015.

[6] Z. X. Zou, C. R. Xiong, Y. K. Wang, H. M. Tang, and J. E. Wang, "An approach to obtain saturated hydraulic conductivity of reservoir landslide," Geotechnical and Geological Engineering, vol. 36, no. 2, pp. 1185-1196, 2018.

[7] S. Zhang, H. M. Tang, X. Liu, Q. W. Tan, and Y. S. Xia-hou, "Seepage and instability characteristics of slope based on spatial variation structure of saturated hydraulic conductivity," Earth Science-Journal of China University of Geosciences, vol. 43, no. 2, pp. 622-634, 2018, in Chinese.

[8] J. A. Sobieraj, H. Elsenbeer, and G. Cameron, "Scale dependency in spatial patterns of saturated hydraulic conductivity," CATENA, vol. 55, no. 1, pp. 49-77, 2004.

[9] A. Zimmermann, D. S. Schinn, T. Francke, H. Elsenbeer, and B. Zimmermann, "Uncovering patterns of near-surface saturated hydraulic conductivity in an overland flow-controlled landscape," Geoderma, vol. 195-196, pp. 1-11, 2013.

[10] Y. Wang, M. A. Shao, Z. Liu, and R. Horton, "Regional-scale variation and distribution patterns of soil saturated hydraulic conductivities in surface and subsurface layers in the loessial soils of China," Journal of Hydrology, vol. 487, pp. 13-23, 2013.

[11] W. Wang, Y. Wang, Q. M. Sun, M. Zhang, Y. X. Qiang, and M. M. Liu, "Spatial variation of saturated hydraulic conductivity of a loess slope in the South Jingyang Plateau, China," Engineering Geology, vol. 236, pp. 70-78, 2018.

[12] X. H. Chen, "Statistical and geostatistical features of streambed hydraulic conductivities in the Platte River, Nebraska," Environmental Geology, vol. 48, no. 6, pp. 693701, 2005. 
[13] X. Chen, H. Mi, H. He et al., "Hydraulic conductivity variation within and between layers of a high floodplain profile," Journal of Hydrology, vol. 515, pp. 147-155, 2014.

[14] D. H. Cheng, X. H. Chen, A. D. Huo, M. Gao, and W. K. Wang, "Influence of bedding orientation on the anisotropy of hydraulic conductivity in a well-sorted fluvial sediment," International Journal of Sediment Research, vol. 28, no. 1, pp. 118-125, 2013.

[15] R. B. Miller, D. M. Heeren, G. A. Fox, T. Halihan, D. E. Storm, and A. R. Mittelstet, "The hydraulic conductivity structure of gravel-dominated vadose zones within alluvial floodplains," Journal of Hydrology, vol. 513, pp. 229-240, 2014.

[16] J. Bevington, D. Piragnolo, P. Teatini, G. Vellidis, and F. Morari, "On the spatial variability of soil hydraulic properties in a Holocene coastal farmland," Geoderma, vol. 262, pp. 294-305, 2016.

[17] C. M. Regalado and R. Muñoz-Carpena, "Estimating the saturated hydraulic conductivity in a spatially variable soil with different permeameters: a stochastic Kozeny-Carman relation," Soil and Tillage Research, vol. 77, no. 2, pp. 189202, 2004.

[18] J. O. Walbrecker and A. A. Behroozmand, "Surface-NMR measurements of the longitudinal relaxation time $\mathrm{T} 1$ in a homogeneous sand aquifer in Skive, Denmark," Journal of Applied Geophysics, vol. 87, pp. 46-52, 2012.

[19] A. A. Behroozmand, K. Keating, and E. Auken, "A review of the principles and applications of the NMR technique for near-surface characterization," Surveys in Geophysics, vol. 36, no. 1, pp. 27-85, 2015.

[20] M. A. Meju, P. Denton, and P. Fenning, "Surface NMR sounding and inversion to detect groundwater in key aquifers in England: comparisons with VES-TEM methods," Journal of Applied Geophysics, vol. 50, no. 1-2, pp. 95-111, 2002.

[21] R. Knight, E. Grunewald, T. Irons et al., "Field experiment provides ground truth for surface nuclear magnetic resonance measurement," Geophysical Research Letters, vol. 39, no. 3, pp. 1-7, 2012.

[22] E. Grunewald, R. Knight, and D. Walsh, "Advancement and validation of surface nuclear magnetic resonance spin-echo measurements of T2," Geophysics, vol. 79, no. 2, pp. EN15EN23, 2013.

[23] X. L. Hu, H. M. Tang, S. Z. Ma, and G. C. Zhang, "Numerical simulation of the 3D landslide stability in three gorges area based on NMR," Earth Science-Journal of China University of Geosciences, vol. 31, no. 2, pp. 279-284, 2006.

[24] M. Hertrich, "Imaging of groundwater with nuclear magnetic resonance," Magnetic Resonance Spectroscopy, vol. 53, no. 4, pp. 227-248, 2008.

[25] W. E. Kenyon, P. I. Day, C. Straley, and J. F. Willemsen, "A three-part study of NMR longitudinal relaxation properties of water-saturated sandstones," SPE Formation Evaluation, vol. 3, no. 3, pp. 622-636, 1988.

[26] D. O. Seevers, "A nuclear magnetic method for determining the permeability of sandstones," in Proceedings of SPWLA 7th Annual Logging Symposium, Tulsa, OK, USA, May 1966.

[27] A. Weller, S. Nordsiek, and W. Debschütz, "Estimating permeability of sandstone samples by nuclear magnetic resonance and spectral-induced polarization," Geophysics, vol. 75, no. 6, pp. E215-E226, 2010.

[28] R. Dlugosch, T. Günther, M. Müller-Petke, and U. Yaramanci, "Improved prediction of hydraulic conductivity for coarsegrained, unconsolidated material from nuclear magnetic resonance," Geophysics, vol. 78, no. 4, pp. EN55-EN64, 2013.
[29] R. Knight, D. O. Walsh, J. J. Butler et al., "NMR logging to estimate hydraulic conductivity in unconsolidated aquifers," Groundwater, vol. 54, no. 1, pp. 104-114, 2016.

[30] D. Y. Li, K. L. Yin, and C. Leo, "Analysis of Baishuihe landslide influenced by the effects of reservoir water and rainfall," Environmental Earth Sciences, vol. 60, no. 4, pp. 677-687, 2010.

[31] J. Du, K. L. Yin, and S. Lasasse, "Displacement prediction in colluvial landslides, three gorges reservoir, China," Landslides, vol. 10, no. 2, pp. 203-218, 2013.

[32] Y. Liu, D. Liu, Z. M. Qin, F. B. Liu, and L. B. Liu, "Rainfall data feature extraction and its verification in displacement prediction of Baishuihe landslide in China," Bulletin of Engineering Geology and the Environment, vol. 75, no. 3, pp. 897-907, 2016.

[33] F. S. Miao, Y. P. Wu, Y. H. Xie, and Y. N. Li, "Prediction of landslide displacement with step-like behavior based on multialgorithm optimization and a support vector regression model," Landslides, vol. 15, no. 3, pp. 475-488, 2018.

[34] S. Zhang, H. M. Tang, H. B. Zhan, G. P. Lei, and H. Cheng, "Investigation of scale effect of numerical unconfined compression strengths of virtual colluvial-deluvial soil-rock mixture," International Journal of Rock Mechanics \& Mining Sciences, vol. 77, pp. 208-219, 2015.

[35] X. H. Long, J. Zhao, Z. P. Liu et al., "Applying geostatistics to determine the soil quality improvement by Jerusalem artichoke in coastal saline zone," Ecologocal Engineering, vol. 70, pp. 319-326, 2014.

[36] J. P. Chiles and D. Pierre, Geostatistics: Modeling Spatial Uncertainty, Wiley, New York, NY, USA, 1999.

[37] P. Goovaerts, Geostatistics for Natural Resources Evaluation, Oxford University Press, New York, NY, USA, 1997.

[38] J. M. Wang, R. X. Yang, and Z. K. Bai, "Spatial variability and sampling optimization of soil organic carbon and total nitrogen for Minesoils of the Loess Plateau using geostatistics," Ecological Engineering, vol. 82, pp. 159-164, 2015.

[39] Geo-Slope International Ltd., Seep/W for Finite Element Seepage Analysis User's Manual, Geo-Slope International Ltd., Calgary, AB, Canada, 1998.

[40] M. Aubertin, M. Mbonimpa, B. Bussiere, and R. P. Chapuis, "A model to predict the water retention curve from basic geotechnical propertie," Canadian Geotechncial Journal, vol. 40, no. 6, pp. 1140-1122, 2003. 


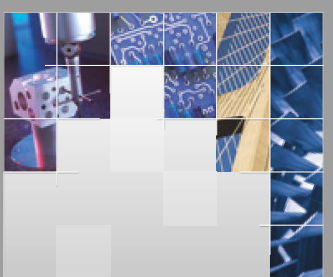

\section{Enfincering}
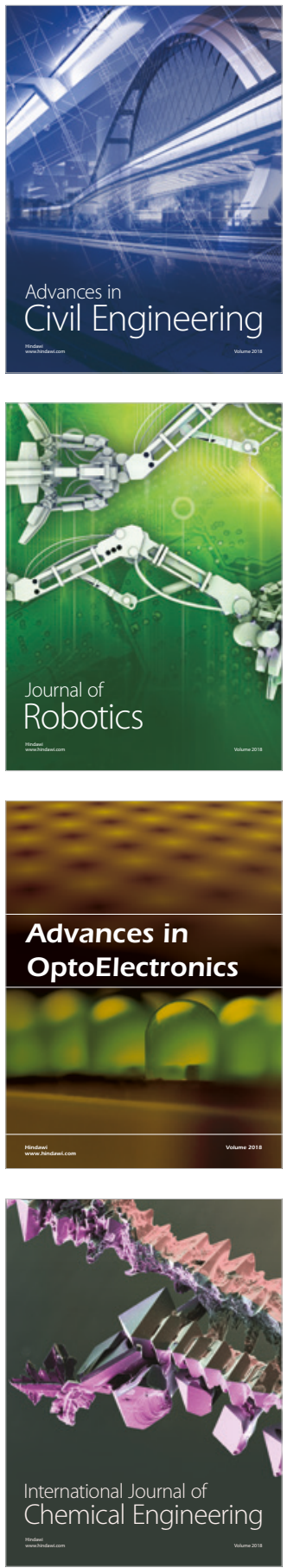

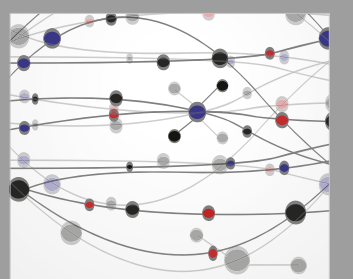

\section{Rotating \\ Machinery}

The Scientific World Journal

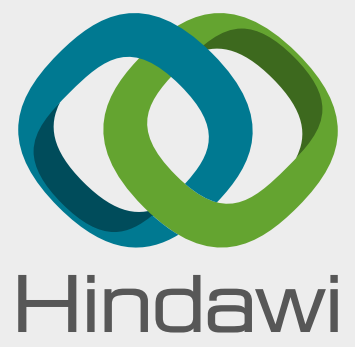

Submit your manuscripts at

www.hindawi.com
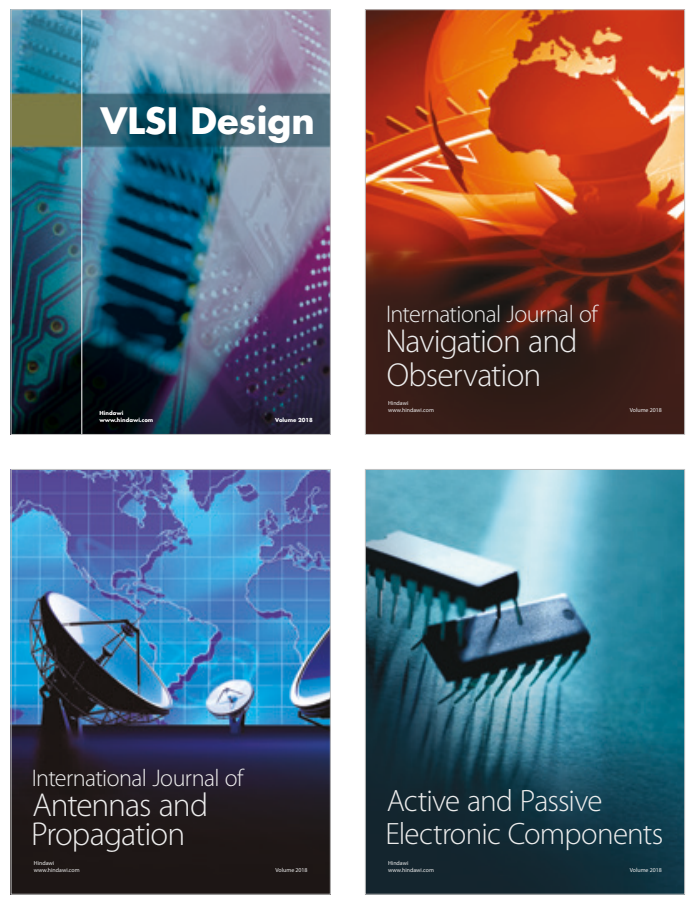
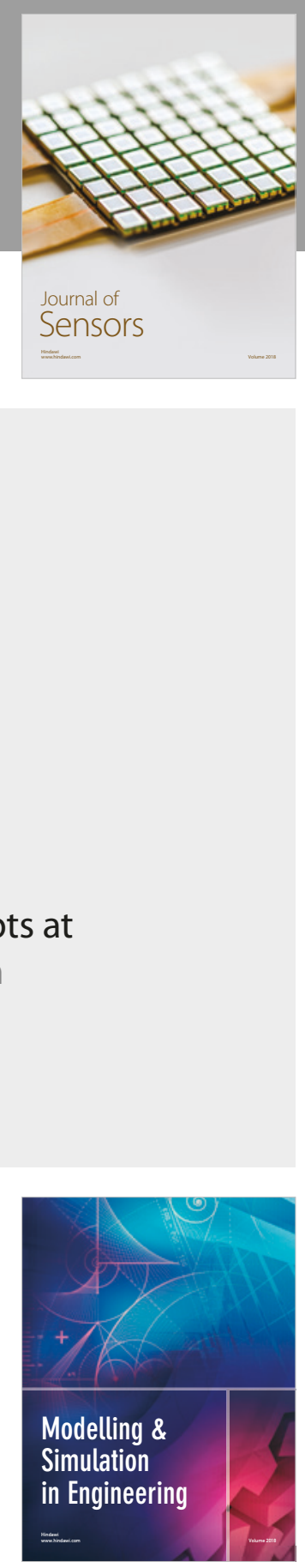

\section{Advances \\ Multimedia}
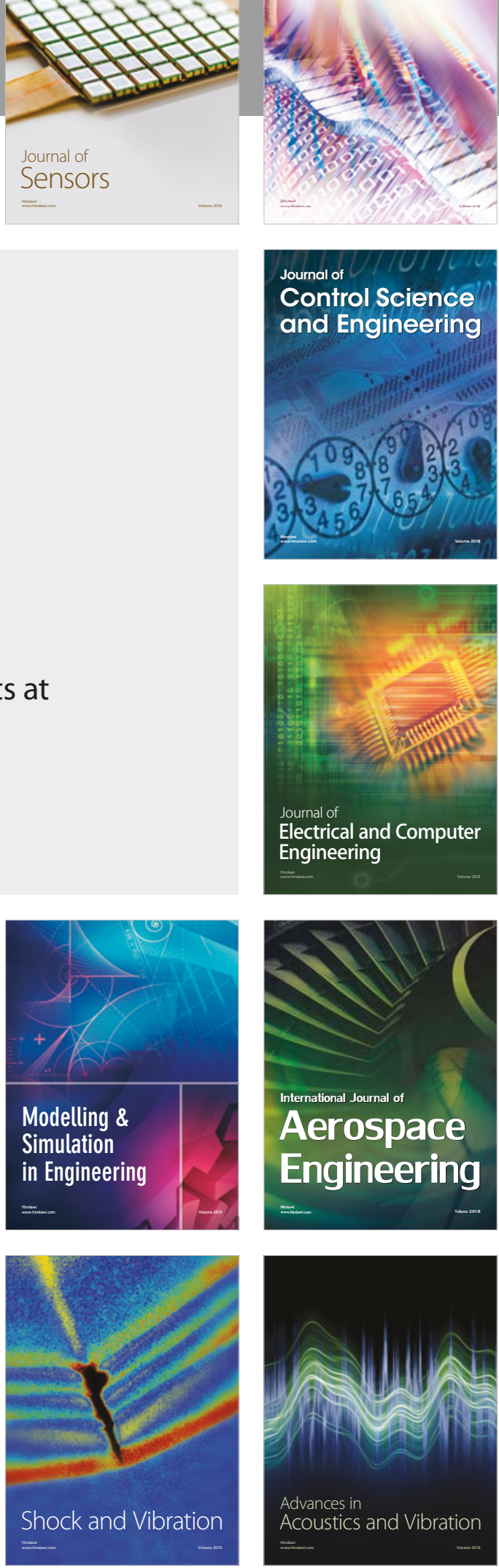